\title{
Dietary advanced glycation end-products exacerbate oxidative stress in patients with diabetic foot ulcers
}

\author{
Haiyan M. Maier', Jasminka Z. Ilich'1, Jeong-Su Kim', Cathy W. Levenson², Bahram H. Arjmandi' and Maria T. Spicer ${ }^{*}$ \\ *Correspondence: mspicer@fsu.edu

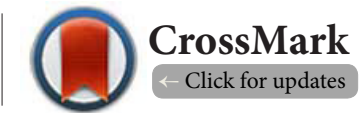 \\ 'Department of Nutrition, Food, and Exercise Sciences, College of Human Science, The Florida State University, Tallahassee, FL, USA. \\ ${ }^{2}$ Department of Biomedical Science, College of Medicine, The Florida State University, Tallahassee, FL, USA.
}

\begin{abstract}
Background: This study examined the association between advanced glycation end-products (AGE) and serum markers of oxidative stress and inflammation in diabetic patients with or without diabetic foot ulcers.

Methods: Eighty-two adult participants were recruited and assigned to one of three groups: 1) non-diabetic control; 2) diabetic participants without foot ulcers (DM); and 3) diabetic participants with foot ulcers (DFU). Demographical data, 24 hour food recalls, and blood samples were collected from each participant. Both dietary and serum AGE were evaluated as well astumor necrosis factor- $\alpha$ (TNF- $\alpha$ ), C-reactive protein (CRP), and thiobarbituric acid reactive substances (TBARS).

$\underline{\text { Results: }}$ The diabetic participants had significantly higher levels of dietary AGE, serum AGE, TNF- $\alpha$, CRP, and TBARS compared to non-diabetic controls. TBARS were significantly higher in DFU than DM. Serum AGE and TBARS were significantly correlated with dietary AGE. Serum TBARS strongly predicted the duration of DFU $\left(\mathrm{R}^{2}=0.52\right)$.

Conclusions: Individuals with DFU had the highest levels of both dietary and serum AGE. Because dietary AGE causes a rise in serum AGE concentration, it is important to reduce the intake of foods containing AGE by promoting appropriate dietary choices in this population.
\end{abstract}

Keywords: Diabetes mellitus, wound healing, obesity, nutrition, inflammation

\section{Introduction}

Diabetic foot ulcer (DFU) is a major and very costly diabetic complication that occurs in patients with a history of poorly controlled blood glucose. Despite newer treatment modalities, DFU is the most common cause of non-traumatic amputation resulting in significant disability [1]. The amputation increases morbidity and mortalityas well as costs associated with medical care, rehabilitation and loss of productivity [2]. Wound healing is compromised in diabetes mellitus especially when wounds are on the extremities. Chronic DFU results from hyperglycemia, neuropathy, vascular insufficiency and diminished neutrophil function in conjunction with an inflammatory and pro-oxidant state resulting in delayed wound healing. A possible risk factor for chronic DFU is the accumulation of advanced glycation end-products (AGE) which form when glucose chemically attaches to proteins without any enzymatic facilitation [3]. The stable end products thus form and affect inside insulindependent cells, cell membrane proteins, circulating proteins, and structural proteins [4].

AGEs are formed endogenously by glucose auto-oxidationand exogenously through heat treatment of food productsduring food preparation. Several factors can affect AGE generation in food including nutrient composition, humidity, $\mathrm{pH}$, temperature and duration of cooking $[5,6]$. Foods with high fat and protein content that undergo high temperature in low humidity generate the greatest amounts of AGE [7]. $\mathrm{N}^{\varepsilon}$-carboxymethyllysine (CML), a common protein-derived and lipid-derived stable AGE, has been well characterized to serve as a marker for AGE in a wide range of disorders related to diabetes, renal failure, and aging [8-10] as well as in food [18].

AGE are elevated in retinal vessels of Streptozotocin (STZ) induced diabetic rats [11] and in the renal glomeruli of patients with diabetic nephropathy [12]. Dietary AGE consumption has been shown to contribute to the total body AGE pool and to have pro-oxidant and pro-inflammatory effects in animals $[13,14]$. However, dietary AGE restriction was found to reduce circulating AGE in patients with diabetes [8], chronic renal failure [9] as well as in healthy elderly [10]. Lower dietary AGE intake was also found tosuppress concentrations of various inflammatory markers, such as tumor necrosis factor- $a$ (TNF- $a$ ) and high sensitive C-reactive protein (hsCRP) $[\mathbf{8}, \mathbf{1 0}]$.

Wound healing is a complex process involving an inflammatory response to injury that results in tissue synthesis and repair. Uncontrolled diabetes mellitusis characterized as a state of pronounced imbalance of pro- and anti- inflammatory cytokines released in a non-sequential manner antagonizing the timely resolution of inflammation [15]. This imbalance impairs the tissue repair process resulting in delayed wound healing. The 
healing process in patients with Diabetes mellitusis affected by the amount of AGE in the body which promotes inflammation and oxidation as demonstrated in animal studies $[14,16]$. In addition, endogenous AGEs are hyperglycemia dependent products with significant pro-oxidant properties manifested by the overproduction of reactive oxygen species and lipid peroxides and a reduction in glutathione, catalase, glutathione peroxidase and superoxide dismutase [4]. It is highly possible that DFU is partially due to unresolved inflammation due to excessive AGE in people with diabetes mellitus [17].

The objectives of this study were to determine whether serum AGE, possibly modulated by dietary AGE intake, constitutes a determinant of inflammation and oxidative stress that contribute to DFU, and to determine dietary and physiological factors in the delayed healing of DFU. The central hypothesis is that elevated serum AGE mayimpair wound healing in patients with DFU by modulating oxidative stress and inflammation.

\section{Participants and methods Participants}

A total of 82 participants were recruited from the Capital Regional Medical Center (CRMC) and Tallahassee Memorial Healthcare (TMH) wound care facilities, the TMH Diabetes Center, and The Florida State University (FSU) wider community. The participants were assigned to three groups based on their health status: 1 ) non-diabetic control group (Control; $n=26) ; 2$ ) participants with type 2 diabetes but without foot ulcer (DM; $\mathrm{n}=26$ ); and 3) diabetic participants with foot ulcer (DFU; $\mathrm{n}=30$ ).

The research protocols were approved by the Human Subjects Committee of The FSU and Institutional Review Boards of CRMC and TMH in Tallahassee, Florida, U.S.A. Written informed consent was obtained from all participants, who met the inclusion criteria, prior to data collection. All data and blood samples except subsequent 24-hour food recalls were collected at the initial visit. One 24-hour food recall was collected during the initial visit and the other two recalls by phone on two different days of the week, including one weekend day, during four weeks after the initial interview. Non-diabetic controls were defined as generally healthy individuals, without diabetes, without direct family members with diabetes, and not taking more than one prescription medication. This group of participants was recruited at FSU. Participants in the DM and DFU groups must have been previously diagnosed with Diabetes Mellitus by a medical doctor. Participants in the DM group were in good glucose control according to self-reported Hemoglobin A1c of less than $7.5 \%$ and free of diabetic complications such as nephropathy retinopathy, and neuropathy. Diabetes participants without foot ulcer were recruited at TMH Diabetes Center. Inclusion criteria for the DFU group were diagnosis of DFU, with open wounds on their foot during the recruitment, and without severe diseases, such as end-stage renal diseases, organ transplants or cancer.

\section{Blood sample collection and processing}

Blood samples from all participants were collected during the time of recruitment. Venous blood samples $(20 \mathrm{~mL})$ were collected from an antecubital vein using a Vacutainer brand collection set (BD Vacutainer, Franklin Lakes, NJ). Blood was left to clot for 30 minutes and centrifuged (4000 rpm. 15 minutes at $4^{\circ} \mathrm{C}$ ) with in two hours of collection using an IEC CL31R multi speed centrifuge (Thermo Electron Corporation, Waltham, MA). Serum samples were then aliquotted and stored at $-80^{\circ} \mathrm{C}$ until analyses.

\section{Biochemical analyses}

Serum AGE was quantified with a monoclonal anti-CML antibody, using enzyme-linked immunosorbent assay (ELISA) commercial kits (Echelon Biosciences Inc. Salt Lake City, UT). Unless otherwise stated, the term serum AGE in the results indicates CML immunoreactivity associated with both proteins and lipids in the blood. TNF-a was measured using commercial ELISA kits with a monoclonal antibody specific for human TNFa. The antibody was raised against recombinant human TNF-a. It has been shown to accurately quantify natural human TNF-a (R\&D Systems, Inc. Minneapolis, MN). C-reactive protein (CRP) was measured using CRP high sensitive ELISA (IBL international, Hamburg, Germany). Lipid peroxides (LPO) were measured using thiobarbituric acid reactive substances (TBARS) assay kits (R\&D Systems, Inc. Minneapolis, MN).

\section{Dietary assessment}

Participants were telephoned on two random days without prior notice following the initial visit. As part of the 24-hour food recalls, both the quantity and type of each food were collected from all participants. Dietary intake was estimated from the average of three 24-hour food recalls of two weekdays and one weekend day using Food Processor SQL 10.6.3 (ESHA Research, Salem, OR). Nutrients included in the analysis were total energy; fat, protein, and carbohydrate, percent of energy from fat, protein, and carbohydrate. Participants were asked to disclose all prescription medications and supplements consumed. Daily dietary AGE content (CML) of the food was estimated utilizing a database of 549 commonly consumed foods [18]. AGE intake was expressed as AGE equivalents/day (1 AGE Eq $=1,000$ kilo units $C M L$ ). In this published database, food samples were tested for AGE with ELISA using a monoclonal anti-CML antibody [18].

\section{Duration of the wounds}

The duration of DFU was defined as spanning from the day of epidermis break-out until the day the ulcer(s) was healed. All 30 DFU participants were followed for 24 months. Wounds from one participant failed to heal by the end of 24 months despite 703 days of clinical monitoring and treatment. An additional three participants underwent amputation of which the resulting surgical wounds were subsequently healed. Two participants were discharged from the wound care center 
due to relocation. Clinical and dietary data of 27 healed DFU participants were used for statistical analyses.

\section{Statistical analyses}

Data were analyzed using the Statistical Package for Social Science (SPSS) version 21.0 (SPSS, Inc., Chicago, IL). All variables were normally distributed. With significance accepted a priori at $p<0.05$ and with the accepted effect size of 0.80 , a minimum of 26 subjects in each group were required to achieve statistical power [19].

Results were presented as mean \pm standard deviation. The designated statistical significance value was set at $p<0.05$ for all tests. Descriptive statistics and comparative one-way ANOVA were conducted to provide population characteristics and to determine differences among groups with post-hoc Bonferroni's correction for multiple comparisons. Correlation analyses were evaluated by Pearson's correlation coefficient. Predictors gleaned from Pearson's correlation and ANOVA were used for generating general linear model to determine factors affectingthe duration of DFU.

Although the wide age variance among participants was not intentional, significant differences were found among the groups even though the same inclusion criteria were applied to all participants (age between 45 and 75years). To eliminate age-related effects, age was used as a cofactor for statistical analyses.

\section{Results}

\section{General characteristics}

(Table 1) descriptive data of relevant characteristics are outlined in Table 1. The age of the study population was $59.2 \pm 8$ years (mean $\pm \mathrm{SD}$ ). The participants with diabetes (DM and DFU) were older than control $(p<0.05)$. The BMI of the DFU group was significantly greater than DM which was significantly greater than control. Similarly, body weight was significantly different among the three groups $(p=0.000)$. Although genders were unevenly distributed in the control and DFU, no significant differences in weight and BMI between males and females in each group were observed. There were more females than males in the control group and more males than females in the DFU group but there were no gender differences within each group for all analyzed parameters. Mean duration of diabetes in the DFU group (18 $\pm 13 y r)$ was significantly greater than mean duration of diabetes in the DM group ( $6 \pm 7 \mathrm{yr}$ ). Self-reported Hemoglobin A1c ranged from $6.5-7.4 \%$ in the DM group, and from $9-14 \%$ in the DFU group. As HbA1c is an indicator of long term exposure to hyperglycemia, this result is in agreement with findings of the UKPDS 35 report by Stratton (2000) which showed that risk of diabetic complications was strongly associated with previous hyperglycemia reflected by $\mathrm{HbA1c}$ levels [31]. Epidemiological studies have shown that hyperglycemia increases the risk of lower limb amputations regardless of age of onset of Diabetes Mellitus [32,33]. However, Adler and colleagues (2009) argue that diabetic foot ulcers is $0.8 \mathrm{~g} / \mathrm{kg}$. Participants with diabetes (DM and DFU) had higher AGE/kcal intake compared with control $(p=0.001)$. The AGE intake of DFU ranged from5.0 - 26.7 Eq/day while that of control ranged from 3.4-19.5 Eq/day. DFU had significantly higher AGE per unit protein $(270 \pm 135 \mathrm{Eq} / \mathrm{g})$, compared with

Table 1.General Characteristicsof the Study Population.

\begin{tabular}{lllll}
\hline Groups & Control & DM & DFU & P value \\
\hline $\mathrm{N}$ & 26 & 26 & 30 & -- \\
\hline Age $(\mathbf{y})$ & & & & \\
\hline Means \pm SD & $56 \pm 7^{\mathrm{a}}$ & $61 \pm 8^{\mathrm{b}}$ & $61 \pm 9^{\mathrm{b}}$ & 0.046 \\
Range & $45-69$ & $48-73$ & $45-74$ & -- \\
\hline Gender & & & & \\
\hline Male/female & $4 / 22$ & $13 / 13$ & $20 / 10$ & -- \\
\hline BMI $\left(\mathbf{k g} / \mathbf{m}^{2}\right)$ & & & & \\
\hline Means $\pm S D$ & $27 \pm 6^{\mathrm{a}}$ & $33 \pm 6^{\mathrm{b}}$ & $36 \pm 8^{\mathrm{c}}$ & 0.000 \\
Range & $19.5-41.8$ & $22.9-47.0$ & $20.4-52.5$ & -- \\
Male & $28 \pm 4$ & $32 \pm 6$ & $37 \pm 10$ & 0.075 \\
Female & $27 \pm 6$ & $35 \pm 6$ & $35 \pm 6$ & 0.001 \\
\hline Weight $(\mathbf{l b})$ & & & & \\
\hline Means $\pm S D$ & $162 \pm 36^{\mathrm{a}}$ & $211 \pm 40^{\mathrm{b}}$ & $244 \pm 66^{\mathrm{c}}$ & 0.000 \\
Range & $118-251$ & $142-286$ & $130-373$ & -- \\
Male & $197 \pm 22$ & $225 \pm 40$ & $263 \pm 72$ & 0.064 \\
Female & $157 \pm 35$ & $197 \pm 37$ & $208 \pm 32$ & 0.000 \\
\hline Diabetes duration $(\mathbf{y})$ & & & & \\
\hline Means $\pm S D$ & $\mathrm{~N} / \mathrm{A}$ & $6 \pm 7^{\mathrm{a}}$ & $18 \pm 13^{\mathrm{b}}$ & 0.000 \\
\hline
\end{tabular}

Note: Different symbols $(\mathrm{a}, \mathrm{b}, \mathrm{c})$ show differences between groups $(p<0.05)$. One-way ANOVA used for differences among groups with post hoc Bonferroni's correction for multiple comparisons. BMI, body mass index; C, non-diabetic controls; DM, participants with Diabetes mellitusbutwithout foot ulcers; DFU, participants with DFU.

are a result of multiple factors with primary healing related to duration of diabetes, age, presence of co-morbidities, compliance and number of ulcers [32]. In an animal study researchers were able to demonstrate the independent effect of hyperglycemia on susceptibility to ischemic necrosis [31].

\section{Comparison of parameters among groups}

(Table 2) energy intake of the DM group was the greatest with an average of $1913 \pm 799 \mathrm{kcal}$ and a range of $893-3739 \mathrm{kcal} /$ day, while energy intake of the DFU group was the lowest with an average of $1394 \pm 432 \mathrm{kcal}$ and a range of $799-2579 \mathrm{kcal} /$ day $(p=0.05)$. Based on body weight, DFU had lower energy intake compared with DM and control $(p=0.001)$. Similarly, DFU had lower protein intake compared to DM and control. DFU had an extremely low protein intake of $0.57 \mathrm{~g} / \mathrm{kg}$ body weight. Both DM and control had adequate protein intake compared to Dietary Reference Intakes (DRI) for adult, which 
Maier et al. Journal of Diabetes Research \& Clinical Metabolism 2014,

$\mathrm{DM}$ and control $(<180 \pm 80 \mathrm{Eq} / \mathrm{g}, p=0.000)$. This suggests that the DFU subjects had AGE-richprotein food choices compared to the other groups.

Body weight was used as a confounder for further statistical analyses, due to the large disparities in weight within and among the groups. Analysis of variance showed that there were significant differences among the three groups in serum AGE, CRP, TNF- $a$, and TBARS as shown in Table 2. However, there were no differences between any two of the three groups for serum AGE when using post hoc Bonferroni's correction for multiple comparisons. DFU had significantly higher serum concentration of CRP than control, but not compared to DM. Participants with diabetes (DM and DFU) had higher serum concentrations of TNF-a compared with control. There were significant differences in serum TBARS concentrations among the groups with DFU having the highest concentration and control having the lowest $(p<0.0001)$. TBARS concentrations of DFU were five times greater than control and 1.5 times greater than DM while DM had 3.4 times greater TBARS than control (Figure 1). Based on information from the manufacturer of the TBARS assay kit, TBARS levels of apparently healthy volunteers ranged from $0.28 \pm 0.22 \mu \mathrm{M}$ which is slightly higher than the non-diabetic controls in this study.

Table 2. Dietary and Biochemical Parameters between Groups.

\begin{tabular}{|c|c|c|c|c|}
\hline Parameters & Control & DM & DFU & ANOVA \\
\hline Dietary & -- & -- & -- & $P$ value \\
\hline Energy & -- & -- & -- & -- \\
\hline Total, Kcal/day & $1654 \pm 510^{\mathrm{ab}}$ & $1913 \pm 799^{a}$ & $1394 \pm 432^{b}$ & 0.008 \\
\hline $\mathrm{Kcal} / \mathrm{kg}$ & $23.2 \pm 7.2^{\mathrm{a}}$ & $20.6 \pm 8.9^{\mathrm{a}}$ & $13.2 \pm 4.1^{\mathrm{b}}$ & 0.000 \\
\hline \multicolumn{5}{|l|}{ Protein } \\
\hline Total, g/day & $72 \pm 25$ & $90 \pm 39$ & $60 \pm 27$ & 0.003 \\
\hline $\mathrm{g} / \mathrm{kg}$ & $1.02 \pm 0.39^{\mathrm{a}}$ & $0.97 \pm 0.45^{\mathrm{a}}$ & $0.57 \pm 0.27^{\mathrm{b}}$ & 0.000 \\
\hline \multicolumn{5}{|l|}{ AGE (CML) } \\
\hline Total, Eq/day & $10.4 \pm 5.2^{\mathrm{a}}$ & $14.2 \pm 4.2^{\mathrm{ab}}$ & $13.9 \pm 4.7^{\mathrm{b}}$ & 0.007 \\
\hline $\mathrm{Eq} / \mathrm{Kcal}$ & $6.3 \pm 3.1^{\mathrm{a}}$ & $9.1 \pm 4.8^{\mathrm{b}}$ & $9.2 \pm 4.7^{\mathrm{b}}$ & 0.001 \\
\hline Eq/g protein & $149.1 \pm 78.9^{a}$ & $179.0 \pm 80.7^{\mathrm{a}}$ & $270.2 \pm 135.3^{b}$ & 0.000 \\
\hline \multicolumn{5}{|l|}{ Biochemical } \\
\hline $\mathrm{AGE}, \mu \mathrm{g} / \mathrm{mL}$ & $1.07 \pm 0.25$ & $1.10 \pm 0.30$ & $1.25 \pm 0.27$ & 0.039 \\
\hline $\mathrm{CRP}, \mu \mathrm{g} / \mathrm{mL}$ & $3.55 \pm 4.66^{\mathrm{a}}$ & $5.33 \pm 5.32^{\mathrm{ab}}$ & $8.48 \pm 9.53^{\mathrm{b}}$ & 0.033 \\
\hline TNF- $\alpha, p g / m L$ & $9.62 \pm 2.90^{\mathrm{a}}$ & $13.55 \pm 4.45^{\mathrm{b}}$ & $12.97 \pm 2.54^{\mathrm{b}}$ & 0.000 \\
\hline TBARS, uM & $0.17 \pm 0.12^{\mathrm{a}}$ & $0.58 \pm 0.39^{\mathrm{b}}$ & $0.90 \pm 0.61^{\mathrm{c}}$ & 0.000 \\
\hline
\end{tabular}

Note: Different symbols $(\mathrm{a}, \mathrm{b}, \mathrm{c})$ show differences between groups $(p<0.05)$. One-way ANOVA used for differences among groups with post hoc Bonferroni's correction for multiple comparisons. AGE, advanced Glycation end products; CRP, C-reactive protein; TNF- $\alpha$, Tumor necrosis factor-alpha; TBARS, thiobarbituric acid reactive substances; $\mathrm{C}$, non-diabetic controls; DM, participants with Diabetes mellitusbutwithout foot ulcers; DFU, participants with DFU.

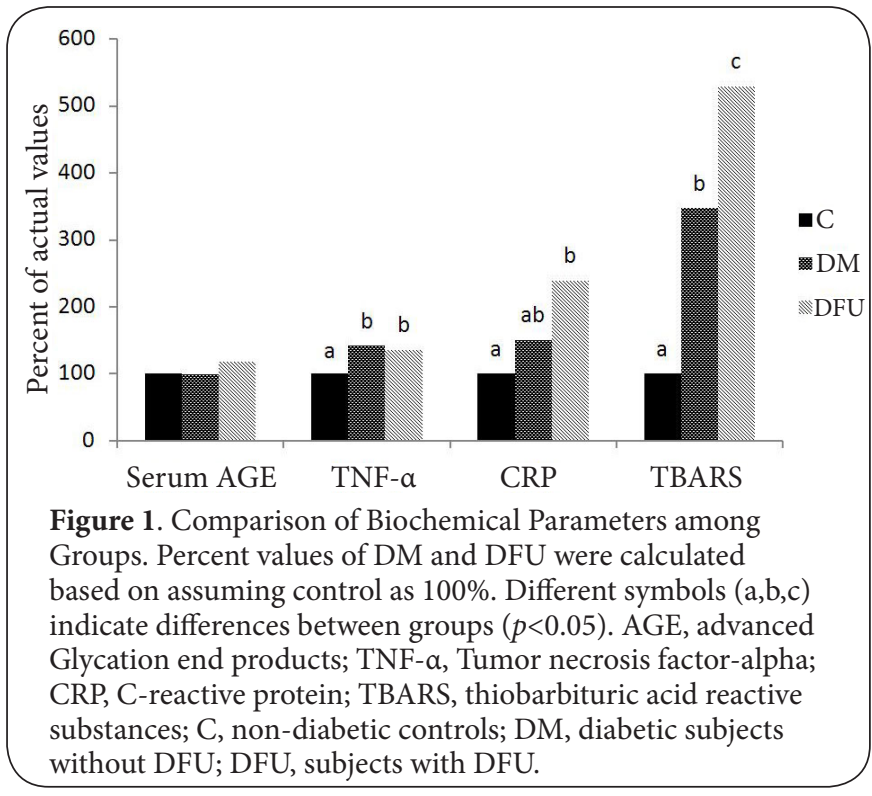

\section{Correlations in the study population}

(Table 3) A positive association between TNF- $a$ and BMI approached significance $(p<0.1)$ while CRP was positively correlated with BMI and body weight. TBARS significantly correlated with $B M I$, body weight and age in years.

Table 3. Correlations between AGE, TNF- $\alpha$, TBARS and Clinical Variables $(\mathbf{n}=82)$.

\begin{tabular}{lllllllll}
\hline & \multicolumn{2}{c}{ dAGE } & \multicolumn{2}{c}{ sAGE } & \multicolumn{2}{c}{ TNF- $\boldsymbol{c}$} & \multicolumn{2}{c}{ CRP } \\
\hline & r & p & r & p & r & p & r & p \\
\hline SAGE & 0.369 & 0.001 & -- & -- & -- & -- & -- & -- \\
TNF- $\alpha$ & 0.280 & 0.016 & 0.356 & 0.002 & -- & -- & -- & -- \\
CRP & 0.038 & 0.751 & 0.164 & 0.165 & 0.321 & 0.006 & - & -- \\
TBARS & 0.571 & 0.000 & 0.338 & 0.003 & 0.267 & 0.023 & 0.309 & 0.008 \\
\hline
\end{tabular}

Note: AGE, advanced Glycation end products; dAGE, dietary AGE; sAGE, serum AGE; CRP, C-reactive protein; TNF- $\alpha$, Tumor necrosis factor-alpha; TBARS, thiobarbituric acid reactive substances; BMI, body mass index. Controlling for weight, BMI, and total energy intake.

Independent of body weight, BMI, and energy intake, dietary AGE intake was positively correlated with serum AGE (Figure 2a) as well as with TNF-a, TBARS (Figure $\mathbf{2 b}$ ), and age in years. Likewise, serum AGE was positively correlated withTNF-a, CRP and TBARS. TNF-a was positively correlated with CRP and TBARS, and, CRP was positively correlated with TBARS.

\section{Serum and dietary AGE (CML), TBARS, TNF- $\alpha$ and DFU Duration}

The healing time of DFU varied from 20 to 286 days. Three DFU participants who healed after toe or below the knee am- 


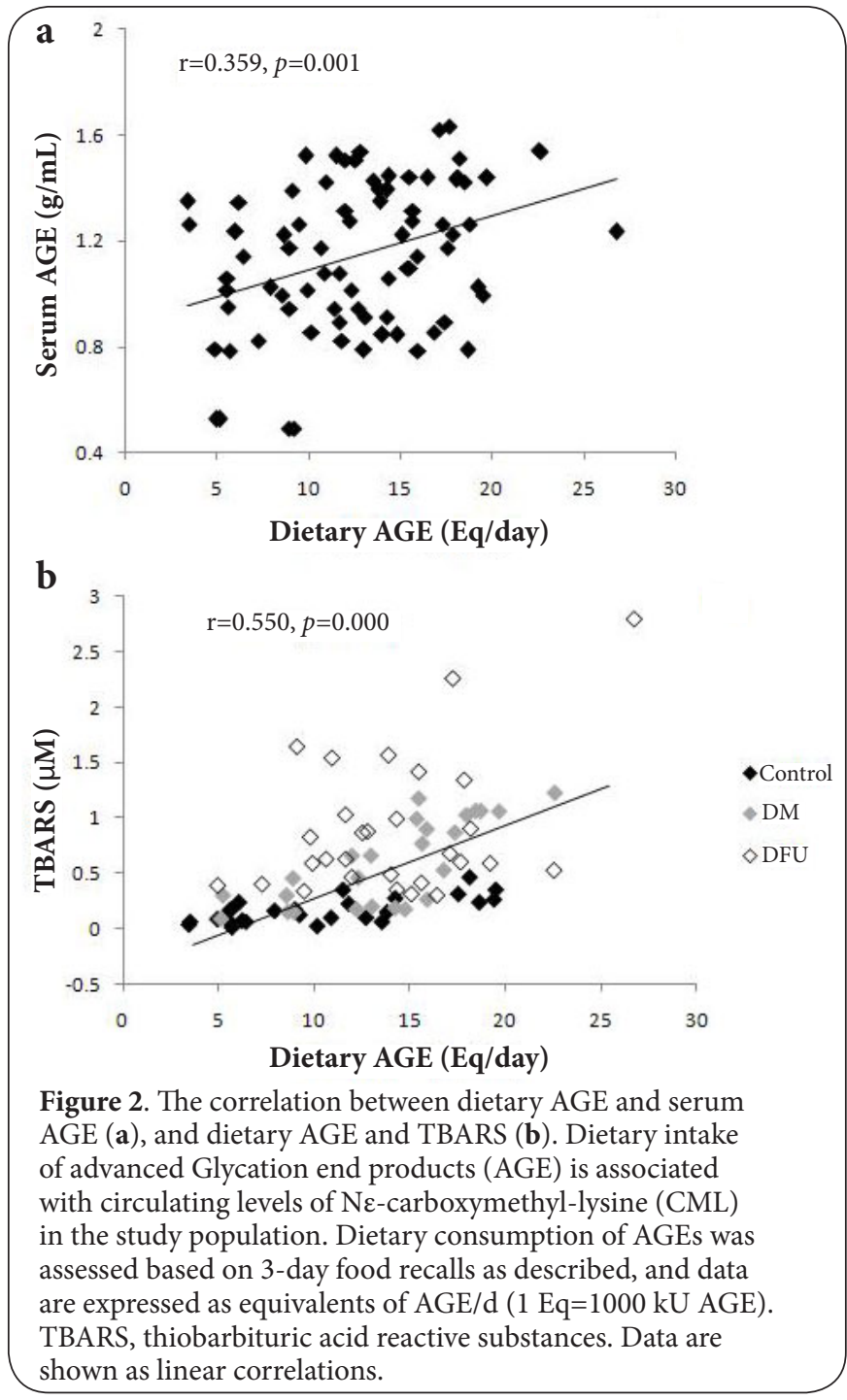

putations were not included in this particular analysis. DFU duration was positively correlated with dietary AGE $(r=0.386$; $p=0.039), C R P(r=0.394 ; p=0.034)$, and TBARS $(r=0.511 ; p=0.005)$. Using stepwise multiple regression modelingto predict DFU duration, the best single predictor for DFU duration was TBARS $\left(R^{2}=0.52\right)$.

\section{Odds ratio for DFU}

Univariate and multivariate logistic regression analyses for presence of DFU in participants with diabetes mellitus showed that among all tested predictors, TBARS and body weight were the best predictors of the presence of DFU. In a single variable analysis, the odds of having a foot ulcer was increased by 4.11 times for every unit increase of TBARS $(p=0.036)$ and by 1.01 times for every unit increase in body weight $(p=0.037)$.

\section{Discussions}

This is the firststudy that examines dietary AGE intake and its relationship with serum AGE, TNF- $a$, CRP, and TBARS in diabetic participants with or without DFU as well as innon-diabetic controls. As a group, diabetic participants had higher $\mathrm{BMI}$, body weight, dietary AGE per unit of energy and serum TNF-a concentration than the non-diabetic controls. This suggests that diet quality should beemphasized in educating and counseling individuals with diabetes mellitus especially in choosing foods that are lower in AGE content as dietary AGE is positively associated with TNF-a. Furthermore, DFU had higher body weight, BMI, and TBARS than DM. Elevated lipid peroxidation has been demonstrated in patient with DFU in other studies $[20,21]$. Overweight and obesity are also highly correlated with oxidative stress [22]. Bodyweight, BMI, and oxidative stress may be key risk factors in the development and prolonged healing time of DFU.

Boyko et al., (1999) identified greater body weight and longer duration of diabetes mellitus asrisk factors for DFU [23]. In this study, the age of DM and DFU participants were similar but DFU had significantly longer duration of diabetes mellitus. This implies that DFU had earlier onset of diabetes, that is, at a younger age, compared to the DM participants. In addition, longer duration of diabetes mellitus, the earlier onset of diabetes mellitusmay also be a risk factor for the development of DFU.

It is highly possible that the inactivity associated with having a foot ulcer had significant effects on body weight in this study despite the lower caloric intake by this group. The DFU participants had lower energy intake and yet greater body weight compared with DM. This can be possibly explained by a lower metabolic rate, sedentary lifestyle and physical inactivity. Indeed, physical activity plays an important role in preventing obesity and improving insulin sensitivity. All these factors may affect, both directly and indirectly, the wound healing process in patients with DFU.

DFU participants in this study also had lower protein intake than DM indicating a poorer diet quality. In addition, AGE per unit of protein consumed by DFU participants were significantly greater than in DM. Qualitative analysis of the DFU food recalls revealed that bacon, fried meat, hot dogs, beef steak, chicken nuggets, pork and beef sausages, which are foods high in AGE, were typical components of the DFU diet. These findings are consistent with foods listed by Vlassara et al., as exceptionally high in AGE content [24]. Although socioeconomic status was not included in this study, it may have an influence on food choices. More alarmingly, protein intake by participants with DFU far below the DRI for protein compared to the other two groups that had adequate protein intake $(0.57 \mathrm{vs} .1 .0 \mathrm{~g} / \mathrm{kg})$ [25]. Adequate protein intake is essential for the integrity of connective tissue, muscle and skin, as well as cutaneous wound healing. Protein deprivation leads to impaired healing in experimental wounds by hindering collagen synthesis and deposition [26]. As shown in an earlier study, patients with non-healing wounds had significantly lower protein intake than patients with healed wounds [27]. 
Thus, there is an increased risk of impaired healing in any patient with insufficient dietary protein intake.

The combination of high AGE intake and weight may have had an additive effect resulting in higher oxidative stress in the participants with DFU. Although DFU and DM exhibited comparable AGE intake, DFU participants were heavier, afflicted with diabetes for a longer duration, had less total energy and protein intake, and demonstrated higher concentrations of TBARS. Dietary glycotoxins intake has been shown to impair wound healing in genetically diabetic mice [14]. In this study prolonged healing time was positively correlated with increaseddietary AGE intake, higher levels of CRP and TBARS suggesting that AGE intake mayimpair the healing of DFU by modulating systemic inflammation and oxidative stress.

Chronic dietary exposure to excessive AGE fosters a proinflammatory state, as evidenced by the strong correlation between dietary AGE withTNF-a. This is consistent with the observation that elevated TNF-a levels were preceded by high AGE content in the diet [8]. In this study, a positive relationship between dietary AGE and TNF-a, further supports the hypothesis that dietary AGE intake, via its effects on serum AGE, modulates inflammation. Efforts should be made to educate people with diabetes to maintain low levels of dietary AGE intake. The binding of AGE with RAGE activates NF-kB which initiates the production of inflammatory cytokines including TNF-a [28].

As observed by others [10], serum AGE has been shown to be correlated with oxidative stress markers such as 8 -isoprostanes. The strong correlation between AGE intake and TBARS in this study is in agreement with other studies that have observed the link between dietary AGE intake and high oxidative stress associated with an increase in glutathione peroxidase activity [29]. TBARS were positively correlated with TNF-a, CRP, BMI, weight and age in years. DFU had significantly greater weight and BMI than DM which are known to correlate with the levels of oxidative stress in the body [30]. Perhaps, the prooxidant and pro-inflammatory environment in conjunction with dietary AGE and body weight collectively contributed to unresolved diabetic wounds. Thus, the combined therapy of decreasing dietary AGE, achieving a healthy body weight, increasing antioxidant intake, and controlling pro-oxidation with medication has promising effects in promoting the healing process and preventing future DFU development.

Diabetic participantsin this study made food choices that were high in AGE content consuming at least one serving of high-AGE foods daily. On the other hand, the control group had diets rich in fresh fruit and vegetables which were lower in AGE content. This may in part explain the lower concentration of inflammatory and oxidative stress markers in non-diabetic participants. AGE accumulation has been implicated as a major factor in the pathogenesis of diabetic complications.

This study demonstrates the positive association between dietary AGE intake and healing time of DFU as well as with serum TBARS. Therefore, reducing oxidative stress by limiting dietary AGE may hasten healing time and prevent the occurrence of DFU.

\section{Competing interests}

The authors declare that they have no competing interests.

Authors' contributions

\begin{tabular}{|l|c|c|c|c|c|c|}
\hline Authors' contributions & HM & JI & JK & CL & BA & MS \\
\hline Research concept and design & $\checkmark$ & $\checkmark$ & $\checkmark$ & $\checkmark$ & -- & $\checkmark$ \\
\hline Collection and/or assembly of data & $\checkmark$ & -- & -- & -- & -- & -- \\
\hline Data analysis and interpretation & $\checkmark$ & -- & -- & -- & $\checkmark$ & $\checkmark$ \\
\hline Writing the article & $\checkmark$ & -- & -- & -- & -- & -- \\
\hline Critical revision of the article & $\checkmark$ & -- & -- & -- & -- & -- \\
\hline Final approval of article & $\checkmark$ & $\checkmark$ & $\checkmark$ & $\checkmark$ & $\checkmark$ & $\checkmark$ \\
\hline Statistical analysis & $\checkmark$ & -- & -- & -- & -- & - \\
\hline
\end{tabular}

\section{Acknowledgement}

We are grateful to the subjects for their participation in this study and the staff of the Capital Regional Medical Center and the Tallahassee Memorial Healthcare for their valuable assistance throughout the project. This study was supported by The Florida State University.

\section{Publication history}

EIC: Geoffrey Burnstock, University College London, UK. Received: 11-Jun-2013 Revised: 24-Oct-13

Re-Revised: 20-Dec-2013 Accepted: 31-Jan-2014

Published: 26-Feb-2014

\section{References}

1. Moulik PK, Mtonga R and Gill GV. Amputation and mortality in newonset diabetic foot ulcers stratified by etiology. Diabetes Care. 2003; 26:491-4. | Article | PubMed

2. Moss SE, Klein R and Klein BE. Long-term incidence of lower-extremity amputations in a diabetic population. Arch Fam Med. 1996; 5:391-8. | Article I PubMed

3. Maillard LC. The action of amino acids on sugar; The formation of melanoidin by a methodic route. Comptes Rendus Hebdomadaires Des Seances De L Academie Des Sciences. 1912; 154:66-68.

4. Brownlee $\mathrm{M}$, Vlassara $\mathrm{H}$ and Cerami A. Nonenzymatic glycosylation and the pathogenesis of diabetic complications. Ann Intern Med. 1984; 101:527-37. | Article | PubMed

5. O’Brien J and Morrissey PA. Nutritional and toxicological aspects of the Maillard browning reaction in foods. Crit Rev Food Sci Nutr. 1989; 28:211-48. | Article | PubMed

6. Goldberg T, Cai W, Peppa M, Dardaine V, Baliga BS, Uribarri J and Vlassara $\mathrm{H}$. Advanced glycoxidation end products in commonly consumed foods. J Am Diet Assoc. 2004; 104:1287-91. | Article | PubMed

7. Adler Al, Boyko EJ, Ahroni JH and Smith DG. Lower-extremity amputation in diabetes. The independent effects of peripheral vascular disease, sensory neuropathy, and foot ulcers. Diabetes Care. 1999; 22:1029-35. I Article | PubMed

8. Vlassara H, Cai W, Crandall J, Goldberg T, Oberstein R, Dardaine V, Peppa $M$ and Rayfield EJ. Inflammatory mediators are induced by dietary glycotoxins, a major risk factor for diabetic angiopathy. Proc Natl Acad Sci U S A. 2002; 99:15596-601. | Article I PubMed Abstract | PubMed Full Text

9. Uribarri J, Peppa M, Goldberg T, Cai WJ, He CJ and Vlassara H. Effect of dietary AGE (advanced glycation end products) modifications on circulating AGE levels in dialysis patients. Journal of the American Society of Nephrology. 2002; 13:595a-595a. 
10. Uribarri J, Cai W, Peppa M, Goodman S, Ferrucci L, Striker G and Vlassara $\mathrm{H}$. Circulating glycotoxins and dietary advanced glycation endproducts: two links to inflammatory response, oxidative stress, and aging. $J$ Gerontol A Biol Sci Med Sci. 2007; 62:427-33. | Article | PubMed Abstract I PubMed Full Text

11. Stitt AW, Li YM, Gardiner TA, Bucala R, Archer DB and Vlassara H. Advanced glycation end products (AGEs) co-localize with AGE receptors in the retinal vasculature of diabetic and of AGE-infused rats. Am J Pathol. 1997; 150:523-31. | PubMed Abstract | PubMed Full Text

12. Horie K, Miyata T, Maeda K, Miyata S, Sugiyama S, Sakai H, van Ypersole de Strihou C, Monnier VM, Witztum JL and Kurokawa K. Immunohistochemical colocalization of glycoxidation products and lipid peroxidation products in diabetic renal glomerular lesions. Implication for glycoxidative stress in the pathogenesis of diabetic nephropathy. J Clin Invest. 1997; 100:2995-3004. | Article | PubMed Abstract | PubMed Full Text

13. Hofmann SM, Dong HJ, Li Z, Cai W, Altomonte J, Thung SN, Zeng F, Fisher $\mathrm{EA}$ and Vlassara $\mathrm{H}$. Improved insulin sensitivity is associated with restricted intake of dietary glycoxidation products in the $\mathrm{db} / \mathrm{db}$ mouse. Diabetes. 2002; 51:2082-9. | Article | PubMed

14. Peppa M, Brem H, Ehrlich P, Zhang JG, Cai W, Li Z, Croitoru A, Thung S and Vlassara $\mathrm{H}$. Adverse effects of dietary glycotoxins on wound healing in genetically diabetic mice. Diabetes. 2003; 52:2805-13. | Article | PubMed

15. Syrenicz A, Garanty-Bogacka B, Syrenicz M, Gebala A and Walczak M. Low-grade systemic inflammation and the risk of type 2 diabetes in obese children and adolescents. Neuro Endocrinol Lett. 2006; 27:453-8. | Article | PubMed

16. Goova MT, Li J, Kislinger T, Qu W, Lu Y, Bucciarelli LG, Nowygrod S, Wolf BM, Caliste X, Yan SF, Stern DM and Schmidt AM. Blockade of receptor for advanced glycation end-products restores effective wound healing in diabetic mice. Am J Pathol. 2001; 159:513-25. | Article | PubMed Abstract | PubMed Full Text

17. Uribarri J, Stirban A, Sander D, Cai W, Negrean M, Buenting CE, Koschinsky $T$ and Vlassara $H$. Single oral challenge by advanced glycation end products acutely impairs endothelial function in diabetic and nondiabetic subjects. Diabetes Care. 2007; 30:2579-82. | Article | PubMed

18. Uribarri J, Woodruff S, Goodman S, Cai W, Chen X, Pyzik R, Yong A, Striker $\mathrm{GE}$ and Vlassara $\mathrm{H}$. Advanced glycation end products in foods and a practical guide to their reduction in the diet. J Am Diet Assoc. 2010; 110:911-16 e12. | Article | PubMed Abstract | PubMed Full Text

19. Cohen J. Statistical power analysis for the behavioral sciences. second edition edn. Hillsdale, Newy Jersey; 1988.

20. Vairamon SJ, Babu M and Viswanathan V. Oxidative Stress Markers Regulating the Healing of Foot Ulcers in Patients With Type 2 Diabetes. Wounds-a Compendium of Clinical Research and Practice. 2009; 21:273279.

21. Bolajoko EB, Mossanda KS, Adeniyi F, Akinosun O, Fasanmade $A$ and Moropane M. Antioxidant and oxidative stress status in type $\mathbf{2}$ diabetes and diabetic foot ulcer. S Afr Med J. 2008; 98:614-7. | Article | PubMed

22. Vincent HK and Taylor AG. Biomarkers and potential mechanisms of obesity-induced oxidant stress in humans. Int J Obes (Lond). 2006; 30:400-18. | Article | PubMed

23. Boyko EJ, Ahroni JH, Stensel V, Forsberg RC, Davignon DR and Smith DG. A prospective study of risk factors for diabetic foot ulcer. The Seattle Diabetic Foot Study. Diabetes Care. 1999; 22:1036-42. | Article | PubMed

24. Valassara H. The AGE-less way. Charleston SC; 2011. | Website

25. IOM. Dietary Reference Intakes: applications in dietary assessment. National Academy Press. 2011.

26. Arnold $\mathrm{M}$ and Barbul A. Nutrition and wound healing. Plast Reconstr Surg. 2006; 117:42S-58S. | Article | PubMed

27. Agrawal S, Pandey SS, Shukla VK and Kaur P. Nutritional and vitamin status of non-healing wounds in patients attending a tertiary hospital in India. J Dermatol. 2003; 30:98-103. | Pdf | PubMed

28. Luevano-Contreras $C$ and Chapman-Novakofski K. Dietary advanced glycation end products and aging. Nutrients. 2010; 2:1247-65. | Article | PubMed Abstract | PubMed Full Text
29. Cai W, Gao QD, Zhu L, Peppa M, He C and Vlassara H. Oxidative stressinducing carbonyl compounds from common foods: novel mediators of cellular dysfunction. Mol Med. 2002; 8:337-46. | PubMed Abstract | PubMed Full Text

30. Mittal PC and Kant R. Correlation of increased oxidative stress to body weight in disease-free post menopausal women. Clin Biochem. 2009; 42:1007-11. | Article | PubMed

31. Stratton IM, Adler Al, Neil HA, Matthews DR, Manley SE, Cull CA, Hadden $D$, Turner RC and Holman RR. Association of glycaemia with macrovascular and microvascular complications of type 2 diabetes (UKPDS 35): prospective observational study. BMJ. 2000; 321:405-12. | Article | PubMed Abstract | PubMed Full Text

32. Adler Al, Erqou S, Lima TA and Robinson AH. Association between glycated haemoglobin and the risk of lower extremity amputation in patients with diabetes mellitus-review and meta-analysis. Diabetologia. 2010; 53:840-9. | Article | PubMed

33. Klein R. Hyperglycemia and microvascular and macrovascular disease in diabetes. Diabetes Care. 1995; 18:258-68. | Article | PubMed

34. Levigne D, Tobalem M, Modarressi A and Pittet-Cuenod B. Hyperglycemia increases susceptibility to ischemic necrosis. Biomed Res Int. 2013; 2013:490964. | Article | PubMed Abstract | PubMed Full Text

\section{Citation:}

Maier HM, Ilich JZ, Kim J-S, Levenson CW, Arjmandi $\mathrm{BH}$ and Spicer MT. Dietary advanced glycation endproducts exacerbate oxidative stress in patients with diabetic foot ulcers. J Diab Res Clin Met. 2014; 3:2. http://dx.doi.org/10.7243/2050-0866-3-2 